\title{
A Survey of Psychological Traits Behind Learning to Design: NOVICES AS DORMANT EXPERT DESIGNERS
}

\author{
G. R. Gress \\ University of Calgary \\ grgress@ucalgary.ca
}

\author{
S. $\mathrm{Li}$ \\ University of Calgary \\ simoli@ucalgary.ca
}

\begin{abstract}
With their increasing emphasis on the importance of hands-on practice and gaining experience, the fields of engineering-design research and education appear to be entering a human-focused transition other fields like economics and decision making have emerged from in the recent past. In addition to the original, modernism-rooted desire for a rational science of design modelled on the natural sciences, this delay may be due the inherently strong association of engineering with science i.e., 'applied science.' This research investigated whether there may instead be a science to the human involvement in design, of the human behaviours that often appear in actual engineering design practice. It surveyed published empirical studies in psychology, child development and other social and life sciences - as well as those within design research itself. Of particular interest were the designer behaviours and activities which did not follow the prescriptions of - or were prescribed against by - the traditional, rational-design methods: visualization, singlesolution conjecturing, and intuition. Results from this survey showed comprehensively that environmental interactions and authentic design experiences activate latent design abilities and coping mechanisms that may be difficult to obtain otherwise. Without such interaction and the gaining of experience there can be no designing, so essentially design is a wholly human phenomenon. Rather than follow the rational-design method and prescribe against these design-enabling behaviours, then, it appears that a better pedagogical approach is to allow them to develop and mature - and let design novices become the experts they were meant to be.
\end{abstract}

Keywords: Design learning; design education; design experience; innate behaviour; prescriptive methodology; engineering pedagogy.

\section{INTRODUCTION}

In the last two decades, economics and decision-making research have departed the world view of scientific rationalism, both discovering that it provides poor models of actual human behaviour and that having people follow them does not necessarily lead to better outcomes [45], [86]. Both fields have since adopted a human-centric stance of observation and understanding rather than of prescription. The study of engineering design appears to be following a similar trend, albeit far more slowly and in a much less unified way [19]. In addition to the original, modernism-rooted desire for a rational science of design modelled on the natural sciences, this delay may be due the strong association of engineering with science - i.e., 'applied science,' with the possible inference being that design must be such a science and a science in its own right.

\subsection{Designer Traits: Limiters or Enablers?}

However, as will be shown in this paper, people have inherent, latent behavioural traits when it comes to designing, and these contribute significantly to the process of design. The authors posit that these behaviours need to be understood so that students can be better guided towards becoming proficient designers.

Towards this goal this paper surveys the psychology, child-development, paleontology, decision-making and design-research literature and discusses how three specific behaviours - visualization, single-solution conjecture, and intuition - manifest themselves in the practice of design. Most are well known and have been viewed by many rational-design method researchers and educators in the past as limitations, those to-be-avoided behaviours and tendencies which cause - or appear to cause - fixation and poor design outcomes. They are found here instead foremost to be design enablers, behaviours which are important to the practice of design. To advocate their avoidance from the beginning, then, is to impose undue burden and difficulty on the student designer.

\subsection{Organization}

It is found too that all of the behaviours are inextricably linked to the gaining of design experience and the accompanying growth of information chunks in the individual's memory - with each trait being automatically engaged or activated with the slightest amount of such experience. It is therefore worthwhile to begin, in Section 2 , with a background discussion of information chunks and their growth. The three identified behavioural are then 
examined in Section 3, and a discourse on the actual gaining of design experience follows in Section 4.

\section{BACKGROUND: INFORMATION CHUNKS}

People possess various devices which enable them to process otherwise overwhelmingly large amounts of information in order to understand and solve problems. One of these devices, described here, is the information chunking mechanism which alleviates the limitations of short-term memory (STM).

\subsection{Information Chunks \& Short-Term Memory}

The amount of information one can hold temporarily in mind is signified by one's STM [63]:118, within which all cognitive processing occurs and therefore from which all problem-solving efforts are governed [68]. The system operates essentially serially, one process at a time rather than in parallel [81] [82], and the inputs and outputs are held in STM with a capacity of only a few symbols. This capacity, of course, is the 'magic number' of seven information chunks [57]. It has enormous ramifications on the degree to which people comprehend new situations and for the role experience plays in gaining that comprehension - that is, how one learns.

\subsection{Information-Chunk Growth with Experience}

The basic property of a chunk is its unity as a familiar pattern [83], a cognitive construct that incorporates multiple lower-level elements of information into a single schema with a specific function [68]. In this way, only the single schema needs to be processed. As designers solve problems, their expertise about the constraints and potential solutions increases and the configuration of chunks becomes more efficient. That is, through transformations, each chunk will represent more and more information as experience is gained. This more encompassing design schema then becomes readily available to the STM. Long-term memory (LTM) stores vast numbers of schemas which can be brought individually to STM as needed. The information stored in LTM is continually being rewritten or revised with new experiences and reflections [80].

\subsection{Protracted Learning Due to Incrementation}

Because of the limited size of the STM, all learning must start with very simple experiences and problems, and with subsequent increases in difficulty lying within this limitation so that they can be incorporated into the schemas or chunks. Indeed, Ericsson [28] observed that students and advanced performers should be presented with cases just above their current level of ability. Each level of learning becomes a foundation for the next; that is, one learns only in terms of what one already knows.

Consequently, the time required for learning is substantial. The small amount of STM available and the time required to move items from it to the essentially infinite-sized LTM - of the order of seconds or tens of seconds - comprise the bottleneck in the system. It is exacerbated by the need to present the stimuli more than once, with distinct pauses in between [3]. Additionally, according to variation theory, some critical aspects of the object of the learning must vary while other aspects remain constant [21].

A further consequence of this is that functions of objects are abstracted from form after witnessing many examples [12] [66].

\subsection{Memory Structures for Problem Solving}

More than just providing additional information per chunk, the learning process affords a memory structure which supports exploration and creativity [66] [52]. These structures not only create a space for learning, they allow learners to anticipate where not-yet-discovered ideas should fit; our brains are hardwired to look for those patterns in what we experience, and the patterns become the basis for future action and learning through transformations, allowing the learner to adapt to new situations and come up with new ideas [1] through further transformations.

Some experience with the problem type must therefore exist prior to its detection [88], which is another way of stating that the learning must be incremental and real. To be able to see, people must know what they are looking for, and be able to predict its appearance. Novices' knowledge representations, in contrast, are irregular, unorganized collections of fragments [76].

With experience, people automatically learn which elements of a situation are important and which can be ignored [25]; only with it can they detect important patterns in the environment [76]. As such, pattern recognition is one of the critical processes underlying expert decision making and problem solving. It makes for easier understanding and expedient selection from an otherwise infinite array of solutions for the competent designer [8]. As Akin [2] notes, discovery consists of not constructing useless combinations, but in constructing those that are useful, and which are in infinitely small minority; it is discernment and selection.

\section{BEHAVIOURS DEFYING PRESCRIPTION}

Eugene Ferguson's 1992 reaction to the 'scientification' of engineering design - the ability to make creative, innovative, yet sound and practical judgements - was that it would be impossible, since engineering design "draws from the experience of patterns initially perceived by the senses" ([47] citing [29]) This reaction is increasingly being subscribed to in recent years based on classroom studies [19] but lacks perhaps a scientific foundation. The literature survey presented here represents an effort to help establish such a foundation. 
The 'experience of patterns' that Ferguson referred to shows itself in the three behaviours dominant in design practice and discussed in the following subsections but which are prescribed against by the rational design methods (e.g., [69] [89] [54]): visualization, early-solution conjecture and intuition.

\subsection{Visualization and Exposure}

The visual-processing areas of the brain are of great assistance when designing, being highly evolved and able to infer meaning to and from imagery, either real or imagined. Recognition and interpretation of situations and artifacts begin automatically in the human visual system [95] using its network of many subsystems, and their visualization cannot be avoided once one has become exposed to them [84].

\subsubsection{Mechanics a Core Domain}

A core domain with which humans start is an implicit understanding of physical-object behaviours and relationships. Infants have the ability to demonstrate expectations regarding the physical properties of objects or goal-oriented animate behaviours, yet their ages do not justify the attribution of these abilities to experiential learning [8]. This core or causal domain is likely the very foundational or first level facilitating learning in terms of what one already knows, referred to in the previous section.

The infant's processing of the physical world organizes quickly around a core structure representing the arrangement of and mechanical relations between threedimensional objects [50]. These findings, in Leslie's [50] view, indicate a specialized learning mechanism adapted to create conceptual knowledge of the physical world at an early period in development. In contrast, infant development in other areas is extremely slow, due to poor planning and structuring abilities [50].

\subsubsection{Autonomous Images}

Studies of children of subsequent years, from infants to teenagers, have shown that abstract reasoning and the power to manipulate symbols arise from actions in exploring and coping with the immediate physical environment, i.e., from experience [46](ch. 1). The growing child's system of knowing changes qualitatively in successively identifiable stages, where in the first, enactive stage, knowledge is represented in concrete actions and is not separable from the experiences that generate it. In the second, iconic stage, knowledge is represented in images that have an increasingly autonomous status from the experiences they represent [46] (ch. 1).

\subsubsection{Emerging Structured Creativity}

The ability to imagine the future - and therefore be creative - depends on past experiences, for studies of the development of children show that they are not able to imagine future scenes until they have gained the ability to recall past experiences, typically between the ages of 3 and 5 [80]. At the same time, however, experience can be considered as guiding; McLellan and Nicholl [56] cite a number of studies across several domains which suggest that thinking is constrained by pre-existing knowledge, such that imagination, rather than being free-roaming, is structured.

\subsubsection{Manifestation in Design}

Oxman [67] has argued that knowledge of visual cognition is central to the understanding of designing. With it, shapes convey meaning and function, and play an important role in our perception and conception [70][53]. We are able to comprehend new shapes and their functions from old ones, an ability which is linked to and enables solution emergence in design [67] [70] - i.e., the creation of problem-solving new shapes. Within the limitations of the STM and the learning and creating devices described in the Section 2, then, exposures increasingly allow one to infer the meaning and function of ever-more complex situations and artifacts. This affords new connections, leading to transformations [11] and hence new knowledge and creativity in design.

Electroencephalography (EEG) experiments performed during conceptual design have shown that experts use more of the visual-spatial regions of their brains than novices do [33]. Good spatial ability significantly promotes design success, but only once the designer has gained tactile experience from which to draw upon [31]. The ability comprises making meaningful interpretations of visual stimuli and of the relations between the stimulus elements [34] [79]:7, which appears an extension of the ability that emerges in childhood.

People therefore tend to visualize design ideas in terms of the real-world artifacts they have had exposure to. Increasing the number of meaningful interactions with such artifacts then produces more with which to visualize and be creative. Conversely, it is apparent that if there have been no exposures then there can be no design solutions, no creativity. No one can interpret, understand or specify an object's function without having witnessed or imagined its implementation in physical form [84] [55] [40]. As has been discussed in the previous section, function is abstracted from multiple exposures, but designers will still first visualize representative embodiment-solutions [45] [84]. Visualization is a latent ability, then, which experience activates and progressively nourishes.

\subsubsection{Predominance in Other Domains}

A good example of this ability in other domains is that chess masters can remember positions of 20-or-so pieces taken from actual games far better than they can random arrangements of pieces ([81]:71-72 citing [37]). This reflects the masters' many prior exposures, whereby inferred meanings and sub-meanings have been previously stored as chunks. Visualization has a strong presence in the field of decision making as well. In his study of 
fireground commanders, Klein [45] found that they evaluated a course of action by using mental simulation to imagine how it would play out within the context of the current situation. If it could work as is, they would initiate the action. Otherwise, they would try to adapt it or consider other actions that were somewhat less typical, continuing until they found an option that felt comfortable.

\subsubsection{What the Rational Design Methods Say}

According to the classical-design methodologist's viewpoint, the wealth of experiences and the aversion to risk in a design office combine to stand in the way of better but unconventional solutions [69]:161. Unconscious, concrete solutions may already reside within its designers, based on possibly fixed or fixated ideas and fictitious constraints. According to this view, designers must therefore very carefully examine whether novel and more appropriate paths are available to them. To solve the problems of fixation and being stuck with conventional ideas, the methodologists instruct the designer to use abstraction, in the sense of ignoring the existing, physical artifact which embodies the function - even a generalized or hypothetical one. From the foregoing discussions, however, this directive is seen as difficult to implement; functions are not universal absolutes but derive from the actions of physical objects, a representative one of which the designer will visualize.

This directive by rational-design methods is intended to have the designer think in higher-level terms, such as the reduction of costs, weight, delivery times etc., since "any one of them is likely to provide the impetus for the discovery of a new and better solution principle" [69]:161. Pahl et al. [69]:162 also state that it "would have been a grave mistake" to begin by immediately thinking of actual solutions.

\subsection{Single-Solution Conjecture}

Just a few cues from a problem are sufficient, however, to evoke a pre-composed solution in the mind of the experienced designer [90][10], and many empirical studies show that experienced designers usually conjecture and iterate only on a single solution, e.g. [49] [52] [22] [39] [85]. This is not to say that they will remain with their first idea no matter the outcome, but that the pursued idea represents their best offering at the time. It is the idea that will be put through successive iterative assessments and refinements - to better adapt it to and understand the problem. At some juncture, if the idea is seen not to work, or not very well, then it will for the most part be dropped and another sought.

The major point here is that designers will not usually carry five-or-so design ideas equally through to completion for comparison. Intuition, wholly arising from experience and discussed in the next section, will have given them a fairly good idea in which direction to proceed.

\subsubsection{Independence from Proficiency Level}

Revealing the phenomenon's presence across proficiency levels, other empirical studies show that student designers tend as well to stop considering alternatives once they have what appears to be a reasonably good idea [24] [61]. This is despite having been recently trained in rational design methods [23], where developing multiple design ideas in parallel is considered a best practice. From their review of empirical studies, Ball et al. [9] concluded that novice and expert designers' solutiondevelopment strategies are similar, showing minimal exploration of alternatives, fixation on initial solution concepts, and iterative solution refinement and patching of concepts that turn out to have weaknesses.

That student and expert behave similarly seems reasonable since all that need be different between them is the degree of problem complexity. Several researchers have posited that their common tendency may be due the recognition of a salient solution idea setting up an inhibitory mechanism within LTM which blocks the processing of other concepts [62] [10]. This would keep the designer focused to better follow a possible solution through to completion before giving up too readily. In its extreme, of course, this can be considered design fixation, preventing searches for near-optimum solutions. In most ill-defined and complex problems, however, there is no single correct solution and there is no universal solution space containing optimums; solutions are contextdependent and derive from the designer's own personal experience and insight [65]. Numerous paths will lead to the same goal or sufficiently similar goals, and will usually involve varying trade-offs in time, risk and resources.

\subsubsection{Field Studies}

From his interviews of twenty system designers of varying experience, Stolterman [85] found that many of them believed that it is very hard to disregard the first idea, with some saying that the analysis to follow should not be seen as an attempt to objectively depict the reality but as a way to develop and test the possibility of the first idea. In Crilly's [18] interviews with designers, the participants considered some aspects of fixation-related behaviour to be essential to their work; that while designers must remain open to the possibility that their ideas are limited or misapplied, they also need to be persistent in developing their budding ideas in the face of negative feedback (Crilly's italics).

Klein [45] observed that positing, mentally simulating and selecting an early solution is a successful approach and the one used most often by decision-making experts. The experienced decision-maker or expert designer will account for all of the higher-level variables such as cost and weight automatically and subconsciously - at least roughly initially. Klein also found that rational training methods and decision-support systems to subvert this early-positing tendency did not improve decision quality and did not get 
adopted in field settings. People found the tools to be cumbersome and irrelevant to the work they needed to do ([45] citing [92]).

\subsubsection{Design Enabler}

From their collection of empirical studies, Ball et al. [10] conclude that the tendency toward minimal solution search in design appears to be a robust and reliable one, and that fundamental cognitive limitations is a reasonable explanation, given the high-information-processing burden that design places upon mental resources. Thus, it is likely that the single-solution conjecture is a coping mechanism, a design enabler in the face of limited abilities. But it is a well-directed and efficient one, as will be seen in the section on intuition.

\subsubsection{Co-evolution of Problem and Solution}

In what appears to be similar to the single-solution trait, upfront clarification and analysis of a design problem are difficult activities for designers to perform as well. Gunther and Ehrlenspiel [38]:87 found that the time spent on pre-analysis did not correlate with the quality of the design, and several researchers have determined that it is difficult for a designer to analyze a problem completely (e.g., [52] [13] [20]). As will be discussed in subsequent sections, this too may be due to the limitations in humans' STM, for it is unlikely that designers will be able to take into account all the different aspects of the problem [7] without offering solutions; it may in fact reflect a process of revising and reformulating information chunks.

Even with such limitations aside, there can be no inherent structure in a situation since one learns the problem in terms of one's own experiences. As Figueiredo [30] observes, "the process of solving a problem becomes identical with the process of understanding its nature, $[\ldots]$ with the information needed to understand the problem depending on the designer's ideas for solving it." In an extreme example of this, Atman \& Bursic [5] found that novices - having no experience and therefore no ideas could not produce quality designs in spite of spending a large portion of their time defining the problem

3.2.5. Early Making Behaviours Persist into Adulthood

Three-to-five-year-olds were observed by Bagiati and Evangelou [8] to everywhere explore, structure, and restructure their interactions with building blocks. Their transfer of construction ideas occurred in almost every building activity, and represents the learning of new, more complex arrangements, which themselves became essential building blocks. Johnsey [41] notes that the product being made by children is often the 'model' for what is to come next; that children model their ideas by physically manipulating the product. They naturally engage in an iterative process of making, evaluating and analyzing, and then making again (improving), and are not capable of planning ideas thoroughly before engaging with the materials [41]. This process is identical to that observed in expert designers by Mosborg et al [59], of implement, evaluate, modify, then implement again.

The making activity stimulates other process skills in children, such as clarifying, specifying and researching, which follow rather than precede the highly attractive making activity [41]. The need to intersperse physicaltasks and planning, rather than being able to thoroughly preplan, is common in adults as well [72] [94], and has relevance to problem scoping and solution conjecture.

\subsubsection{A Note on Creativity}

Creativity had no simple definition in psychology [71] until fairly recently [74], with most creativity researchers now agreeing that it can be considered in terms of the outcomes of novelty and usefulness [64] [77] [42] [60] [87]. Those researchers do not, however, consider quantity of ideas - or fluency - to be a measure of creativity, contrary to what some design researchers believe.

\subsubsection{Rational Design's Point of View}

For example, Yilmaz et al. [93], referring only to a 50year-old inquiry ([15]), state that "fluency has long been used as a measure of creative ability [...], and generating more ideas will logically allow the solution of a better idea from the start." Similarly, Pahl et al. [69]:78 begin their textbook section Solution Finding Methods by stating that a range of possible solutions for the given task has to be generated, and Ulrich \& Eppinger further this by advocating for thinking of as many solutions as possible [89]:128-131. In their own current reproach of designers' tendencies, McCahan et al. [54] state that "weak designers go with one of their first ideas and develop it without fully considering the alternatives. Strong designers recognize that there are likely to be many solutions and that they will have to use creativity methods and structured thinking to generate a complete set of feasible solutions from which to choose. Practicing these creativity methods will help you develop the ability to generate many diverse solutions to a problem." The creativity methods that McCahan et al. propose practicing, however, do not involve actual design experiences and practice; the importance of these to the individual's future designing will be discussed in Section 4.1.

The reason for the rational-design methodologists' advocating the generation of many ideas - or idea fluency - is that the problem space will be explored more effectively, thereby increasing the chances of achieving successful outcomes ([35] citing [19]). However, as was seen in Sections 2.2.1 and 2.2.4, there is no problem space per se, except that which is defined by the designer's own experiences.

\subsection{Intuition}

Salas et al. [76] refer to conscious deliberation as a "low capacity" channel which can be quickly overwhelmed by large amounts of information. Intuitive processing, however, is subconscious and automatic, and parallel in 
nature and rapidly integrates and organizes complex sets of clues and data. Rather than a random or psychic phenomenon, it is a powerful and evolved [6] coping mechanism, enabling quick decision-making and found to be correct most of the time [45] [76]. Only when the task is simple or has clear criterion for success will deliberation be more effective than intuition [76].

\subsubsection{Mechanism and Manifestation}

Arising from the gaining of experience in the domain [44], intuition is in part an extension or furtherance of pattern matching [75] [76] [45], the recognition of patterns related to the problem and stored in long-term memory. Most importantly, intuition affords the ability to engage in simulated implementation of the solution for evaluation [76].

But expert ability or intuition partly manifests itself as emotions, revealed as a 'feel' for choosing what to do [26] [6] [27]. It is largely based on implicit learning ([76] citing [51]), especially from feedback and the environment, and also automaticity ([76] citing [58]). Automaticity prevents cognitive resources from being wasted on what has been seen or experienced before, allowing the decision maker to direct cognitive resources towards aspects of a situation that are novel [76].

\subsubsection{Time Compression but Not Irrationally}

The primary purpose of intuition, then, is expediency, for it compresses years of experience and learning into mere seconds [6] [75] [44]. Though, as discussed above, intuition has an emotional component, it is not an irrational process [44]. According to Dreyfus \& Dreyfus [25], this emotional involvement does not interfere with detached rule testing and lead to irrational decisions. The opposite, in fact, appears to be the case. Badke-Schaub \& Eris [6] suggest that all humans possess basic intuitive behaviours, and that they are primarily linked to survival mechanisms.

\subsubsection{Advanced View of Intuition?}

One cited observation is that intuition could be a form of intelligence at a level that cannot be accessed with rational thought. According to this view, intuition consists of accessing this internal foundation and eliciting from it a response, or an urge to do something - without being able to understand consciously how the answer is arrived at [44]. Research has indicated that, because of the subtle quantitative and qualitative balances intuition can embrace, it is probably superior to purely rigorous quantitative and rational-analytical models of decision making because of the assumption of linearity ([44] citing [73]).

\subsubsection{Deliberate Practice}

Salas et al. [76] note that, though intuition is based on extensive experience within a domain, certain experiences are more productive for its development than others. Experts across many domains (e.g., chess, the performing arts, sports) engage in particular practice activities called deliberate practice. Ericsson [28] identified four of its conditions as:

- Repetition of the same or similar tasks.

- The presence of immediate feedback that can guide performance improvements, including feedback from an individual who is experienced and knowledgeable in the domain ([76] citing [16]).

- Engaging in tasks that build upon the learner's preexisting knowledge.

- Motivation to engage in practice and performance improvement activities. Experts are intrinsically motivated by their projects and continue practicing in the absence of extrinsic rewards for doing so ([76] citing [43]).

\subsubsection{Adding Analysis to Intuition for Completeness}

Decision making in its complete form is considered a dual process, a balance of intuition and analysis [34] [49], and engineering design is likely no different. Pattern matching is the intuitive part, and simulation - mental or otherwise - and the application of engineering laws and heuristics are the conscious and analytical part. A purely intuitive strategy, relying only on pattern matching, would be too risky because sometimes it would generate flawed options. In contrast, a completely analytical strategy would be too slow [6] [45] and possibly be unconnected to the local environment. A balanced strategy would be one as described by Schank [78] for education, that engineering students learn engineering fundamentals and develop engineering intuition by relating abstract engineering theory to their interactions with hardware.

\subsubsection{What the Rational-Design Methodologies Say}

Pahl et al. [69]:82 acknowledge the possibility of designers seeking and discovering solutions using intuition: "solutions come to them in a flash after a period of search and reflection." They warn, however, that purely intuitive methods have disadvantages since the right idea does not always come at the right time [69]:83. Since it cannot be forced, they say, current conventions and personal prejudices may inhibit original developments, and, because of inadequate information, new technologies or procedures may fail to reach the consciousness of the designer. Pahl et al. suggest instead what they consider to better, formal ideation methods - e.g., Brainstorming, Method 635, Gallery Method; Delphi Method; Synectics; Combination of Methods - which are meant to encourage an association of ideas, with the intention of driving the good ones into consciousness [69]:83. Almost all of these methods, however, involve design groups having multiple members, with each member required to possess substantial domain experience. Individual intuition will still play a dominant role, therefore, so the methods can in fact be considered a means of combining those intuitions. Any considerations of non-experiential creativity methods like Synectics, however, are deferred once more to Section 4.1. 


\section{EXPERIENCE CENTRAL}

Almost immediately upon commencing this survey, and in a multitude of ways, experience with one's environment emerged as central to effective engineering design. There appears to be no substitute for it, and there ultimately can be no avoiding it. In hindsight this is not surprising, considering that design essentially concerns changing that environment.

Based on the foregoing subsections, on visualization, solution conjecture and intuition - and their ubiquitousness - it can be surmised that some human design abilities are latent, and activated or released with the gaining of domain experience. For this reason, the corresponding behaviours are termed here traits. The yet-to-be-filled memory regions of our brains are structured to learn and store experiences and new knowledge so that they are easily searched and recombined for solving new, as-yet unseen problems - and for learning some more.

\subsection{Real Design Experiences}

For such activities to be possible, the past experiences must be in the domain, real or tactile, and relevant to the task or problem at hand. Visser [90] refers to them as actual design activities, those which are "really" implemented in design projects. Gedenryd [32] calls authentic design activities those which confer an ability to design and achieve a successful design outcome.

The cycle designers undergo by testing their new ideas through such representational means as prototyping, tinkering, sketching and conversing - and then evaluating the results and subsequently revising - constitutes this ability [59]. It appears to comprise the unavoidable learning and gaining of experience which both arise from and define the ability to design. With them comes the recognition of ever-more complex, meaning-based patterns and problems.

\subsection{Paleolithic Roots}

It may seem now obvious as to why experience in the domain is necessary for designing, but it is interesting and possibly worthwhile to note how the need likely arose in human beings in the past. The following stems from a survey of paleolithic and primatology research in environments and innate knowledge.

\subsubsection{From Flexibility, a Need to Learn Almost All}

Surviving in highly varied environments required our Paleolithic ancestors to be flexible in their responses to variations in raw materials and their procurement, transportation and use [48]. While many activities of other animal species look intelligent in the human sense, their development is likely very specific and under 'tight genetic guidance' [14]. A good example is the beaver, which, after 60 million years of evolution, can build a near-perfect dam the first time, without instruction or observation [91].
Rather than be so adapted to all of their various past environments, humans invoke intelligence instead. It implies having the ability to represent the changing social and physical processes which occur around us and, from those mental representations, undertake appropriate actions [14] using intrinsic learning and reasoning circuits [17].

But if flexibility confers an ability to solve problems within many domains without prior, innate adaptation to them, then the individual must gain knowledge about the particular one in which they work or reside. According to Byrne [14], some possible methods of gaining this knowledge generally are instruction, observation, imitation, and trial and error - all of which are relevant to engineering and design as well.

\subsubsection{Inflexible Core: Mechanics}

One commonality in all earthly environments, however, is the physical and mechanical behaviour of the objects each contains. It would make sense, then, for infants to be born with innate expectations of this behaviour - as was shown to be the case and discussed in Section 3.1.1 - just as the beaver is born with an innate ability to build dams. Such predispositions save a lot of child-development time and resources, allowing for experiences with the particular environment to be gained and focused on instead.

\subsection{Past Pedagogy: No Design Experience}

In the past, engineering-design pedagogy had not considered student's experiences as being critical to learning to design [36]. By following instead the dictums of the rational design methods, which prescribe intermediary tasks such as forming combinatorial matrices for idea generation and selection, the influences of real artifacts could be avoided ([66] citing [4]), and a lot of time saved creating new ones - or so this was the intent ([96]:4 citing [69]). The methods now seem an attempt to enable design without designing, to instill design methods in the non-practiced.

But the rational-design methods go further than just not acknowledging the need for domain experience. By advocating to strip students of their natural cognitive coping devices - like visualization, single-solution conjectures and intuition - the methods place an extra cognitive burden on students attempting to design. They likely also confuse students by attempting to distance them from true acts of designing.

\section{CONCLUSIONS}

The behavioural traits that designers exhibit and that were studied in this survey appear to be natural ones which are latent but activated with tactile design experience. They progressively enable more complex problem-solving in design, which derives from the very act of practicing it. 


\subsection{Novices are Dormant Expert Designers}

To instruct designers - novice and otherwise - to not visualize, or not to trust their growing intuition, and to think of many design solutions in parallel is, in essence, instructing them not to be human. But, as this research survey shows, people are essentially dormant expert designers to begin with, since experience activates several latent design abilities and coping mechanisms. Allowing these to mature rather than denying them will afford the development of novices into the expert designers they always could be.

\section{Acknowledgements}

This research is supported by the NSERC Chair in Design Engineering.

\section{References}

[1] R. Adams et al., "Multiple Perspectives on Engaging Future Engineers," J. Eng. Educ., vol. 100, no. 1, pp. 48$88,2011$.

[2] O. Akin, "Necessary conditions for design expertise and creativity," Des. Stud., vol. 11, no. 2, pp. 107-113, 1990.

[3] J. R. Anderson, The architecture of cognition. New York: Psychology Press, 1983.

[4] L. B. Archer, "The structure of design process," in Design Methods in Architecture, G. Broadbent and A. Ward, Eds. New York: George Wittenborn, 1969.

[5] C. J. Atman and K. M. Bursic, "Teaching Engineering Design: Can Reading a Textbook Make a Difference?," Res. Eng. Des., vol. 8, pp. 240-250, 1996.

[6] P. Badke-Schaub and O. Eris, "A theoretical approach to intuition in design: Does design methodology need to account for unconscious processes?," in An anthology of theories and models of design, A. Chakrabarti and L. Blessing, Eds. London: Springer, 2014, pp. 353-370.

[7] P. Badke-Schaub and J. Stempfle, "Analysis of solution finding processes in design teams," in Human Behaviour in Design, U. Lindemann, Ed. Berlin: Springer-Verlag, 2003, pp. 121-131.

[8] A. Bagiati and D. Evangelou, "Practicing engineering while building with blocks: identifying engineering thinking," Eur. Early Child. Educ. Res. J., vol. 24, no. 1, pp. 67-85, 2016.

[9] L. Ball, N. J. Lambell, S. E. Reed, and F. J. M. Reid, "The Exploration of Solution Options in Design: A 'Naturalistic Decision Making' Perspective," 2001.

[10] L. Ball, L. Maskill, and T. Ormerod, "Satisficing in engineering design: causes, consequences and implications for design support," Autom. Constr., vol. 7, pp. 213-227, 1998.

[11] A. M. Barry, "Perceptual aesthetics: Transcendent emotion , neurological image," Vis. Commun. Q., vol. 13, no. 3, pp. 134-151, 2006.

[12] T. A. Björklund, "Initial mental representations of design problems: Differences between experts and novices," Des. Stud., vol. 34, no. 2, pp. 135-160, Mar. 2013.

[13] D. Braha and O. Maimon, "The Design Process: Properties , Paradigms , and Structure," Syst. Humans, vol. 27, no. 2, pp. 146-166, 1997.

[14] R. W. Byrne, "Primate Intelligence," in Handbook of Paleoanthropology, vol. 2, W. Henke and I. Tattersal, Eds. Berlin Heidelberg New York: Springer-Verlag, 2007, pp. 1273-1293.

[15] P. M. Clark and H. L. Mirels, "Fluency as a Pervasive Element in the Measurement of Creativity," J. Educ. Meas., vol. 7, no. 2, pp. 83-86, 1970.

[16] I. Cornford and J. Athanasou, "Developing expertise through training," Ind. Commer. Train., vol. 27, no. 2, pp. 10-18, 1995.

[17] L. Cosmides and J. Tooby, "Better than Rational: Evolutionary Psychology and the Invisible Hand," Am. Econ. Rev., vol. 84, no. 2, pp. 327-332, 1994.

[18] N. Crilly, "Fixation and creativity in concept development: The attitudes and practices of expert designers," Des. Stud., vol. 38, pp. 54-91, May 2015.

[19] D. P. Crismond and R. S. Adams, "The informed design teaching and learning matrix," J. Eng. Educ., vol. 101, no. 4, pp. 738-797, 2012.

[20] N. Cross, "Expertise in design: An overview," Des. Stud., vol. 25, no. 5, pp. 427-441, 2004.

[21] S. R. Daly, R. S. Adams, and A. M. Bodner, "What does it mean to design? A qualitative investigation of design professionals' experiences," J. Eng. Educ., vol. 101, no. 2, pp. 187-219, 2012.

[22] J. Darke, "The primary generator and the design process," Des. Stud., vol. 1, no. 1, pp. 36-44, 1979.

[23] M. Deininger, S. R. Daly, K. H. Sienko, and J. C. Lee, "Novice designers' use of prototypes in engineering design,” Des. Stud., vol. 51, pp. 25-65, 2017.

[24] E. Van Dooren, E. Boshuizen, J. Van Merriënboer, T. Asselbergs, and M. Van Dorst, "Making explicit in design education: Generic elements in the design process," Int. J. Technol. Des. Educ., vol. 24, no. 1, pp. 53-71, 2014.

[25] H. L. Dreyfus and S. E. Dreyfus, "Peripheral Vision: Expertise in Real World Contexts," Organ. Stud., vol. 26, no. 5, pp. 779-792, 2005.

[26] S. E. Dreyfus, "The Five-Stage Model of Adult Skill Acquisition," Bull. Sci. Technol. Soc., vol. 24, no. 3, pp. 177-181, 2004.

[27] K. Ehrlenspiel, "On the importance of the unconscious and the cognitive economy in design," in Human Behaviour in Design, U. Lindemann, Ed. SpringerVerlag, 2003, pp. 25-41.

[28] K. A. Ericsson, "Deliberate practice and acquisition of expert performance: A general overview," Acad. Emerg. Med., vol. 15, no. 11, pp. 988-994, 2008.

[29] E. S. Ferguson, Engineering and the Mind's Eye. Cambridge, MA: MIT Press, 1992.

[30] A. D. De Figueiredo, "Toward an Epistemology of Engineering," Work. Philos. Eng. (WPE 2008), no. November, pp. 94-95, 2008.

[31] G. Fricke, "Successful Individual Approaches in Engineering Design," Res. Eng. Des., vol. 8, pp. 151165, 1996.

[32] H. Gedenryd, How designers work - making sense of 
authentic cognitive activities. Lund University, 1998.

[33] M. H. Göker, "The effects of experience during design problem solving," Des. Stud., vol. 18, no. 4, pp. 405426, 1997.

[34] G. Goldschmidt, "Not from Scratch: The DMS Model of Design Creativity," Des. Creat. 2010, pp. 63-70, 2011.

[35] C. M. Gray, S. McKilligan, S. R. Daly, C. M. Seifert, and R. Gonzalez, "Using creative exhaustion to foster idea generation," Int. J. Technol. Des. Educ., 2017.

[36] G. R. Gress, S. Li, and R. W. Brennan, "Experiential learning vs. systematic prescriptions in engineering design: A crossroads for education," in Canadian Engineering Education Association 2018, 2018, pp. 18.

[37] A. D. De Groot, Thought and Choice in Chess. Walter de Gruyter GmbH \& Co., 1978.

[38] J. Günther and K. Ehrlenspiel, "How do designers from practice design?," in Designers: The Key to Successful Product Development, London: Springer-Verlag, 1997, pp. 85-97.

[39] B. Hillier, J. Musgrove, and P. O’Sullivan, "Knowledge and Design," Environ. Des. Res. Pract., vol. 2, pp. 1-14, 1972.

[40] D. G. Jansson and S. M. Smith, "Design fixation," Des. Stud., vol. 12, no. 1, pp. 3-11, 1991.

[41] R. Johnsey, "The place of the process skill making in design and technology: Lessons from research into the way primary children design and make," IDATER95 Int. Conf. Des. Technol. Educ. Res. Curric. Dev., pp. 15-20, 1995.

[42] R. E. Jung et al., "Neuroanatomy of creativity," Hum. Brain Mapp., vol. 31, no. 3, pp. 398-409, 2010.

[43] R. Karniol and M. Ross, "The Effect of PerformanceRelevant and Performance-Irrelevant Rewards on Children ' $s$ Intrinsic Motivation The Effect of Performance-Relevant and Performance-Irrelevant Rewards on Children' s Intrinsic Motivation," Child Dev., vol. 48, no. 2, pp. 482-487, 1977.

[44] N. Khatri and A. Ng, "The role of intuition in strategic decision making," Hum. Relations, vol. 53, no. 1, pp. 57-86, 2000.

[45] G. Klein, "Naturalistic Decision Making," Hum. Factors, vol. 50, no. 3, pp. 456-460, 2008.

[46] D. A. Kolb, Experiential Learning: Experience as The Source of Learning and Development. Englewood Cliffs, NJ: Prentice Hall, Inc., 1984.

[47] E. Kranakis, "Review of 'Engineering and the Mind's Eye' by Eugene S Ferguson," Technol. Cult., vol. 35, no. 2, pp. 402-404, 1994.

[48] S. L. Kuhn and M. C. Stiner, "Middle Paleolithic "Creativity," in Creativity in Human Evolution and Prehistory, S. Mithen, Ed. London: Routledge, 1998.

[49] B. Lawson, How designers think: the design process demystified, Fourth. Burlington, MA: Elsevier Architectuall Press, 2005.

[50] A. M. Leslie, "ToMM, ToBy, and Agency: Core architecture and domain specificity," in Mapping the mind: Domain specificity in cognition and culture, L. A. Hirschfeld and S. A. Gelman, Eds. Cambridge, UK: Cambridge University Press, 1994, pp. 119-148.

[51] M. D. Lieberman, "Intuition: A social cognitive neuroscience approach.," Psychol. Bull., vol. 126, no. 1, pp. 109-137, 2000

[52] P. Lloyd and P. Scott, "Discovering the design problem," Des. Stud., vol. 15, no. 2, pp. 125-140, 1994.

[53] D. Marr, Vision. San Francisco: Freeman, 1982.

[54] S. McCahan, P. Anderson, M. Kortschot, P. E. Weiss, and K. A. Woodhouse, Designing Engineers: An Introductory Text. Hoboken, NJ: John Wiley \& Sons, Inc., 2015.

[55] R. McCormick, "Conceptual and Procedural Knowledge," Int. J. Technol. Des. Educ., vol. 7, no. 12, pp. 141-159, 1997.

[56] R. McLellan and B. Nicholl, "'If I was going to design a chair, the last thing i would look at is a chair': Product analysis and the causes of fixation in students' design work 11-16 years," Int. J. Technol. Des. Educ., vol. 21, no. 1 , pp. 71-92, 2011.

[57] G. Miller, "The magical number seven, plus or minus two: some limits on our capacity for processing information," Psychol. Rev., vol. 101, no. 2, pp. 343$352,1956$.

[58] A. Moors and J. De Houwer, "Automaticity: A theoretical and conceptual analysis," Psychol. Bull., vol. 132, no. 2, pp. 297-326, 2006.

[59] S. Mosborg, R. Adams, R. Kim, C. J. Atman, J. Turns, and M. Cardella, "Conceptions of the Engineering Design Process: An Expert Study of Advanced Practicing Professionals," ASEE 2005 Annu. Conf. , p. 27, 2005.

[60] M. D. Mumford, "Taking Stock in Taking Stock," Creat. Res. J., vol. 15, no. 2-3, pp. 147-151, 2003.

[61] W. C. Newstetter and W. M. McCracken, "Novice conceptions of design: Implications for the design of learning environments," in Design Knowing and Learning:Cognition in Design Education, C. Eastman, W. Newstetter, and M. McCracken, Eds. Elsevier, 2001.

[62] J. B. Nikander, L. A. Liikkanen, and M. Laakso, "The preference effect in design concept evaluation," Des. Stud., vol. 35, no. 5, pp. 473-499, Sep. 2014.

[63] B. Oakley, Mindshift: Break through obstacles to learning and discover you hidden potential. Tarcher Pedigree, 2017.

[64] G. R. Oldham and A. Cummings, "Employee Creativity : Personal and Contextual Factors at Work," Acad. Manag. J., vol. 39, no. 3, pp. 607-634, 2016.

[65] J. Orasanu and T. Conolly, "The Reinvention of Decision Making," in Decision Making in Action: Models and Methods, G. A. Klein, J. Orasanu, R. Calderwood, and C. E. Zsambok, Eds. Norwood, NJ: Ablex, 1993, pp. 3-20.

[66] R. Oxman, "Prior knowledge in design: a dynamic knowledge-based model of design and creativity," Des. Stud., vol. 11, no. 1, pp. 17-28, 1990.

[67] R. Oxman, "The thinking eye: Visual re-cognition in design emergence," Des. Stud., vol. 23, no. 2, pp. 135164, 2002.

[68] F. Paas, A. Renkl, and J. Sweller, "Cognitive Load Theory and Instructional Design: Recent Developments," Educ. Psychol., vol. 38, no. 1, pp. 1-4, 2003.

[69] G. Pahl, W. Beitz, J. Feldhusen, and K.-H. Grote, Engineering Design: A Systematic Approach. London: Springer-Verlag, 2007. 
[70] J. A. Park and Y. S. Kim, "Visual Reasoning and Design Processes," in International Conference on Engineering Design, ICED '07, 2007, pp. 1-12.

[71] H. B. Parkhurst, "Confusion, Lack of Consensus, and the Definition of Creativity as a Construct," J. Creat. Behav., vol. 33, no. 1, pp. 1-21, 1999.

[72] L. H. Phillips, V. E. Wynn, S. McPherson, and K. J. Gilhooly, "Mental planning and the Tower of London task," Q. J. Exp. Psychol. Sect. A Hum. Exp. Psychol., vol. 54, no. 2, pp. 579-597, 2001.

[73] J. Prietula, Michael and H. A. Simon, "Experts in your midst," Harv. Bus. Rev., no. January-February 1989, pp. 120-124, 1989.

[74] M. A. Runco and G. J. Jaeger, "The Standard Definition of Creativity," Creat. Res. J., vol. 24, no. 1, pp. 92-96, 2012.

[75] E. Sadler-Smith, "The Role of Intuition in Collective Learning and the Development of Shared Meaning," Adv. Dev. Hum. Resour., vol. 10, no. 4, pp. 494-508, 2008.

[76] E. Salas, M. A. Rosen, and D. DiazGranados, "Expertise-based intuition and decision making in organizations," J. Manage., vol. 36, no. 4, pp. 941-973, 2010.

[77] P. Sarkar and A. Chakrabarti, "Assessing design creativity," Des. Stud., vol. 32, no. 4, pp. 348-383, Jul. 2011.

[78] R. C. Schank, Dynamic memory: A theory of reminding and learning in computers and people. Cambridge University Press, 1982.

[79] D. A. Schön, "Designing as reflective converstion with the materials of a deisgn situation," Knowledge-Based Systems, vol. 5, no. 1. pp. 3-14, 1991.

[80] M. E. P. Seligman, P. Railton, R. F. Baumeister, and C. Sripada, Homo Prospectus. Oxford University Press, 2016.

[81] H. Simon, The Sciences of the Artificial, 3rd ed. Cambridge, MA: MIT Press, 1996.

[82] H. A. Simon and A. Newell, "Human Problem Solving: the state of the theory in 1970," Am. Psychol., vol. 2, no. 2, p. 169, 1971.

[83] J. F. Sowa, Conceptual Structures: Information processing in mind and machine. Addison-Wesley, 1984.

[84] M. Stacey and K. Lauche, "Thinking and representing in design," in Design Process Improvement: A Review of Current Practice, J. Clarkson and C. Eckert, Eds. Engineering Design Centre, University of Cambridge, 2005, pp. 198-229.

[85] E. Stolterman, "How system designers think about design and methods: Some Reflections Based on an Interview Study," Scand. J. Inf. Syst., vol. 4, no. 1, 1992.

[86] R. Thaler, Misbehaving: The Making of Behavioural Economics. New York: W. W. Norton, 2015.

[87] G. Thompson and M. Lordan, "A review of creativity principles applied to engineering design," Proc. Inst. Mech. Eng. Part E J. Process Mech. Eng., vol. 213, no. 1, pp. 17-31, 1999.

[88] G. Tracy, "Learning to See," Am. Sci., vol. 106, no. 4 , pp. 242-249, 2018.

[89] K. T. Ulrich and S. D. Eppinger, Product Design and Development, 5th ed. McGraw-Hill Irwin, 2012.
[90] W. Visser, "Dynamic Aspects of Design Cognition: Elements for a Cognitive Model of Design," 2004.

[91] L. Wilsson, My Beaver Colony. New York: Doubleday and Co., Inc., 1968.

[92] J. Yates, E. Veinott, and A. Patalano, Hard decisions, bad decisions: On decision quality and decision aiding, no. January. 2003.

[93] S. Yilmaz, S. R. Daly, C. M. Seifert, and R. Gonzalez, "How do designers generate new ideas? Design heuristics across two disciplines," Des. Sci., vol. 1, no. 1992, pp. 1-29, 2015.

[94] R. J. Youmans, "Design fixation in the wild: Design environments and their influence on fixation," J. Creat. Behav., vol. 45, no. 2, pp. 101-107, 2011.

[95] S. Zeki, "Artistic Creativity and the Brain," Adv. Sci., vol. 293, no. 5527, pp. 51-52, 2001.

[96] H. Birkhofer, Ed., The Future of Design Methodlogy. Springer, 2011. 